\title{
Born to be Happy? The Etiology of Subjective Well-Being
}

\author{
Meike Bartels · Dorret I. Boomsma
}

Received: 18 March 2009/Accepted: 4 August 2009/Published online: 3 September 2009

(C) The Author(s) 2009. This article is published with open access at Springerlink.com

\begin{abstract}
Subjective Wellbeing (SWB) can be assessed with distinct measures that have been hypothesized to represent different domains of SWB. The current study assessed SWB with four different measures in a genetically informative sample of adolescent twins and their siblings aged 13-28 years $(N=5,024$ subjects from 2,157 families). Multivariate genetic modeling was applied to the data to explore the etiology of individual differences in SWB measures and the association among them. Developmental trends and sex differences were examined for mean levels and the variance-covariance structure. Mean SWB levels were equal in men and women. A small negative effect of age on mean levels of SWB was found. Individual differences in SWB were accounted for by additive and nonadditive genetic influences, and non-shared environment. The broad-sense heritabilities were estimated between 40 and $50 \%$. The clustering of the four different measures (quality of life in general, satisfaction with life, quality of life at present, and subjective happiness) was explained by an underlying additive genetic factor and an underlying non-additive genetic factor. The effect of these latent genetic factors on the phenotypes was not moderated by either age or sex.
\end{abstract}

Keywords Subjective wellbeing - Happiness · Multivariate modeling · Heritability · Twin-sibling design

Edited by Chandra Reynolds.

M. Bartels $(\bowtie) \cdot$ D. I. Boomsma

Department of Biological Psychology, VU University,

Van der Boechorststraat 1, 1081 BT Amsterdam,

The Netherlands

e-mail: m.bartels@psy.vu.nl

\section{Introduction}

Subjective Wellbeing (SWB) can be assessed with a series of measures representing distinct concepts such as satisfaction with life, happiness, quality of life, and life fulfillment. These concepts represent the affective (Diener and Emmons 1984) and cognitive evaluation (Andrews and Withey 1976) of one's life. SWB has been defined as the total sum of the cognitive and emotional reactions that people experience when they compare what they have and do in life with their aspirations, needs, and other expectations (Calman 1984). This definition is in line with the description given by Diener et al. (1999) that explains SWB as a broad category of phenomena that includes people's emotional responses, domain satisfaction, and global judgments of life satisfaction.

Over the years several attempts have been undertaken to evaluate the specificity and overlap of the concepts that fall under the umbrella of SWB, with most research done on quality of life and satisfaction with life. These concepts have, for example, been of importance for the evaluation of the quality and outcome of health care. Several analyses suggest that quality of life and satisfaction with life can be interchangeably used (Dijkers 2005, 2007; Ferrans 1996; Meeberg 1993; Zhan 1992), but should be contrasted to happiness, which is a more temporary and short-term affective state (Moons et al. 2006). A major distinction between satisfaction with life and quality of life versus happiness is that happiness fluctuates significantly across time and may change from day to day, while satisfaction with life and quality of life have a larger degree of consistency (Diener et al. 1997). This aspect of time fluctuation is also captured in the time-sequential framework of subjective well-being as proposed by Kim-Prieto, Diener (2005). They suggest that distinct measures of SWB are 
interrelated over time, starting with events and circumstances that lead to emotional reactions and memory of emotions, and ending with global judgments. There is further evidence that multiple concepts of wellbeing are distinct. Andrews and Withey (1976) found, for example, that life satisfaction formed a separate factor form positive affect and this finding was replicated 20 years later (Lucas et al. 1996). Research on the overlap of SWB and personality showed that distinct personality traits map onto separate components of SWB (Larsen and Ketelaar 1991). Genetic variance underlying individual differences in SWB is responsible for individual differences in Neuroticism, Extraversion, and, to a lesser extent, Conscientiousness (Weiss et al. 2008). The latter study also found evidence for a general genetic factor underlying individual differences in the five personality domains and subjective wellbeing and the authors hypothesize that personality acts as a kind of affective reserve that might be relevant to stability and change of the SWB set point over time.

Often, distinct measures, such as satisfaction with life, happiness and quality of life, are interchangeably used, even within studies, to provide information on SWB. For example, quality of life is often used to assess SWB in large-scale world-wide investigations in different countries, such as the Health Behavior in School aged Children study (HBSC; WHO, 2008) and the large scale UNICEF study (Innocenti Research Centre 2007). In these projects participants were asked to rate quality of life, using the 10-step Cantril Ladder (Cantril 1965). The top of the ladder indicates the best possible life, and the bottom, the worst possible life. In the HBSC study high life satisfaction, with a score of "6" or more on the 10-point ladder, was common among young people. Between ages 11 and 15, there was a significant decline in levels of life satisfaction with a more pronounced effect in girls than boys. Boys reported high life satisfaction more often than girls at ages 13 and 15 (Currie et al. 2008). In parallel, UNICEF reported that the great majority of young people growing up in OECD (organization for economic co-operation and development) countries scored themselves above the midpoint on the 'life satisfaction ladder' and life satisfaction decreased between the ages of 11 and 15, particularly girls. More specifically, the Netherlands head the table of overall well-being, and the United States and United Kingdom close it. Although, mean differences in well-being between different countries are impressive, the variance between countries actually is substantially smaller than the variance within countries. The causes of these individual differences in well-being have been described in six studies and knowledge about the etiology of SWB could provide new opportunities to develop prevention and intervention programs for those who are less happy and satisfied with their life. If happiness of these people could be slightly increased it could result in better mental and physical health, more effective coping and in the longer end longevity (Tugade and Fredrickson 2004; Cohn et al. 2009).

The six studies that investigated the etiology of SWB showed significant heritability estimates in the range of 40 $50 \%$. The remaining variance was accounted for by environmental influences unique to an individual (Tellegen et al. 1988; Lykken and Tellegen 1996; Røysamb et al. 2002, 2003; Stubbe et al. 2005; Nes et al. 2006). The study by Tellegen et al. (1988) used the well-being scale of the Multidimensional Personality Questionnaire, and reported non-additive genetic effects. These findings were replicated by Lykken and Tellegen (1996). Røysamb et al. (2002) employed the short version of the subjective well-being scale (Moum et al. 1990) and found no evidence for nonadditive genetic effects. This study and a study with a larger sample conducted 1 year later (Røysamb et al. 2003) presented quantitative sex-differences, with somewhat larger heritability estimates for women (54\%) than for men (46\%). The most recent study (Nes et al. 2006) with a partly overlapping dataset found heritability estimates $42-56 \%$ and reported sex-specific additive genetic and nonshared environmental effects. The longitudinal design of this last study enabled investigation of underlying sources of stability and found a 6 year stability of SWB that was mainly attributable to stable additive genetic factors (Nes et al. 2006). Finally, a study by Stubbe et al. (2005), in a large twin-sibling sample reported a broad sense heritability of $38 \%$ for satisfaction with life, measured with the satisfaction with life scale (Diener et al. 1985). Non-additive genetic effects explained almost all of the genetic influences. No sex-differences were found.

The studies on subjective wellbeing (Tellegen et al. 1988; Lykken and Tellegen 1996; Røysamb et al. 2002, 2003; Nes et al. 2006), or on satisfaction with life (Stubbe et al. 2005) have not addressed question if the distinct constructs of well-being (satisfaction with life, subjective happiness, and quality of life) have different etiologies, or whether they are just distinct descriptions of a single latent SWB concept. Genetic influences have been reported for both satisfaction with life as well as subjective wellbeing and based on the rather high phenotypic correlation between the constructs, a high genetic overlap might be expected as well.

All studies on individual differences in well-being were conducted in adults. We report on a large-scale study in adolescents and young adults, aged 12-23 years. We assessed four measures of SWB, Quality of life in general, Satisfaction with life, Quality of life at present, and Subjective happiness in over 2000 twin pairs and their nontwin siblings. Using multivariate, genetic structural equation modeling we aim to answer the following questions. 
1. What are the causes of individual differences for each of the four measures of SWB?

2. Are there quantitative and/or qualitative sex differences in the genetic architecture of these measures?

3. Is there a change in the magnitude of genetic and environmental factors from age 12 to age 23 ?

4. To what extent are the four measures associated?

5. Are associations among measures explained by common genetic or common environmental influences?

\section{Method}

Subjects

Participants were registered at birth with the Netherlands Twin Registry (NTR), established by the Department of Biological Psychology at the VU University in Amsterdam (Boomsma et al. 2006; Bartels et al. 2007). Between registration and adolescence information on childhood emotional and behavioral problems was collected from parental and teacher reports. When the twin pair reached the age of 13 parents were asked for informed consent to contact the adolescent twins and their non-twin siblings (aged 12 years and older). Next a self-report survey was collected in adolescence in twins (mean age: 15.55, $\mathrm{SD}=1.5$ ) and siblings (mean age: $17.09, \mathrm{SD}=3.1$ ). The sample for this study consisted of 2,015 first-born twins, 2,037 second-born twins, 438 singleton brothers and 534 sisters ( $N=5,024$ individuals; $45 \%$ male) from 2,157 families. The overall family response rate was $56.1 \%$.

A maximum of two siblings (one brother and one sister) per family were included in the analyses. A few families $(n=20)$ had data on more than one sibling of the same sex. From these families data from the sibling closest in age to the twin was selected for analyses. Zygosity was determined for 461 samesex twin pairs by DNA analysis or blood group polymorphisms. For all other same-sex twin pairs, zygosity was determined by discriminant analysis, using longitudinal questionnaire items from the previously collected parental report. Agreement between zygosity assignment by the replies to the longitudinal questionnaire and zygosity determined by DNA markers/blood typing was around 93\% (Rietveld et al. 2000). The sample consisted of 321 complete MZM twin pairs, 264 complete DZM pairs, 449 complete MZF pairs, 326 complete DZF pairs, 263 male-female pairs and 240 femalemale pairs, and 326 twins of incomplete pairs.

\section{Measures}

The Dutch Health Behavior Questionnaire (DHBQ) is a self-report instrument which assesses health, lifestyle, and behavior. It includes four measures of SWB.
1. Quality of life in general $\left(\mathrm{QL}_{\mathrm{g}}\right)$ was assessed with the Cantril Ladder (Cantril 1965). It has ten steps: the top indicates the best possible life, and the bottom the worst possible life. Participants were asked to indicate the step of the ladder at which they place their lives in general.

2. Satisfaction with life (SAT) was assessed with the five item Satisfaction with Life Scale (Diener et al. 1985). Example items are: "My life is going more or less as I wished" and "I'm satisfied with life." Participants were asked to answer at a 7-point likert scale with 0 indicating strongly disagree and 7 indicating strongly agree.

3. Quality of life at the moment of measurement $\left(\mathrm{QL}_{\mathrm{p}}\right)$ was also assessed with the Cantril Ladder (Cantril 1965). Participants were asked to indicate the step of the ladder at which they would place their lives at the moment.

4. Subjective Happiness (HAP) was assessed with the 4-item Subjective Happiness Scale (Lyubomirsky and Lepper 1999). On a 7-point likert scale, adolescents had to indicate whether they agreed or disagreed with statements like: "On the whole I'm a happy person" and "On the whole, I'm not very happy".

\section{Analyses}

Genetic structural equation modeling in $\mathrm{Mx}$ (Neale et al. 2006) was used with the raw-data Maximum Likelihood procedure for estimation of parameters. Nested submodels were compared by hierarchic $\chi^{2}$ tests. The $\chi^{2}$ statistic is computed by subtracting $-2 \mathrm{LL}$ (log-likelihood) for the full model from that for a reduced model $\left(\chi^{2}=-2 \mathrm{LL}_{1}-\right.$ $\left.\left(-2 L_{0}\right)\right)$. Given that the reduced model is correct, this statistic is $\chi^{2}$ distributed with degrees of freedom (df) equal to the difference in the number of parameters estimated in the two models $\left(\Delta \mathrm{df}=\mathrm{df}_{1}-\mathrm{df}_{0}\right)$. In addition to the $\chi^{2}$ test statistic, Akaike's Information Criterion (AIC $=\chi^{2}-2 \mathrm{df}$ ) was computed. The lower the AIC, the better the fit of the model to the observed data.

\section{Descriptive statistics and correlations}

First, for each measure means, variances, and the effects of sex and age on the means were estimated. A covariance matrix was estimated conditional on zygosity and sex, which provides information on covariances among measures and family members, to gain insight into the sources of individual differences and the underlying sources of overlap between the distinct measures of SWB. 
Genetic modeling

Monozygotic (MZ) twins derive from a single zygote and are (nearly always) genetically identical. Less than perfect MZ twin correlations $\left(\mathrm{r}_{\mathrm{MZ}}<1\right)$ indicate environmental effects that are not shared between children growing up in the same family. Dizygotic (DZ) twins develop from two zygotes and, like non-twin siblings, share on average $50 \%$ of their segregating genes. A higher resemblance of $\mathrm{MZ}$ versus DZ twin pairs and twin-sibling correlations therefore may reflect the higher genetic similarity and indicates genetic effects. The design allows the estimation of environmental influences common to or shared by twins and siblings growing up in the same family. These shared environmental influences are implied if the resemblance between twin and sibling pairs exceeds the resemblance expected on the basis of quantitative genetic theory. When the DZ correlation is higher than the twin-sibling correlation, a specific environment might exist which is shared by twins but not by non-twin siblings (Eaves et al. 1999).

Multivariate data of twins and siblings provide the opportunity to decompose the variance of a trait as well as the covariance among traits into additive and non-additive genetic, shared environmental, and nonshared environmental components. Additive genetic factors (A) represent the sum of the effects of alleles over all loci that influence the trait. Non-additive genetic factors concern interactions between alleles, which can occur in two ways. Non-additive genetic factors (D) represent interaction between alleles at the same locus (dominance) or interaction between alleles at the different loci (epistasis). Shared environmental factors (C) are the part of the variance that is shared by members of family and nonshared environmental factors (E) is the part of the total variance that is unique to a certain individual. Nonadditive genetic effect and shared environmental effects are confounded in the classical twin (sibling) design and are therefore estimated in separate models. Based on the literature and the correlations we from hereon continue with models considering additive genetic, non-additive genetic, and nonshared environmental effects only.

Age and sex effects

In order to test for developmental changes and sex-differences on the genetic architecture of the four SWB measures a moderator model (Purcell 2002) was expanded to use in an extended twin-sibling design (see Fig. 1). The influence of A (latent additive genetic factor), D (latent non-additive genetic factors) and $\mathrm{E}$ (latent nonshared environmental factor) on the phenotypes are represented by paths $\mathrm{a}+\beta_{x a} M_{1}+\beta_{y a} M_{2}, \mathrm{~d}+\beta_{x d} M_{1}+\beta_{y d} M_{2}, \quad$ and $\mathrm{e}+\beta_{x e}$ $M_{1}+\beta_{y e} M_{2} \cdot M_{1}$ represents the sex of an individual (coded 0 for men, 1 for women) and $M_{2}$ represents age in years. The value of $M_{1}$ and $M_{2}$ changes from subject to subject, taking on the value of the measured sex and age variable for that subject. If the $\beta$ 's are significantly different from zero, there is evidence for a moderating effect on the latent factors. In other words, the moderation model allows a test whether the importance of additive genetic effects (a), nonadditive genetic effects (d), and unique environmental effects (e) are changing as a linear function of sex and/or age. The pathway $\mu+\beta_{x m} M_{1}+\beta_{y m} M_{2}$ represents main effects of the moderator variables on the outcome, i.e. the effect of sex and age on mean levels of SWB.

Correlated factor, common pathway, and independent pathway models

To gain a first insight into the possible underlying sources of covariance among the fours measures of SWB, a
Fig. 1 The moderator model. Squares represent measured variables, and circles represent latent, unobserved factors. The triangle represents the mean. The additive genetic, nonadditive genetic and nonshared environmental value is a linear function of the moderator $M_{1}$ and $M_{2}$, for A represented by the equation $a+\beta_{\mathrm{x}} M_{1}+\beta_{\mathrm{y}} M_{2}$, where $\beta_{x}$ and $\beta_{y}$ are the unknown parameters to be estimated from the data, representing the magnitude of the sex and age effects

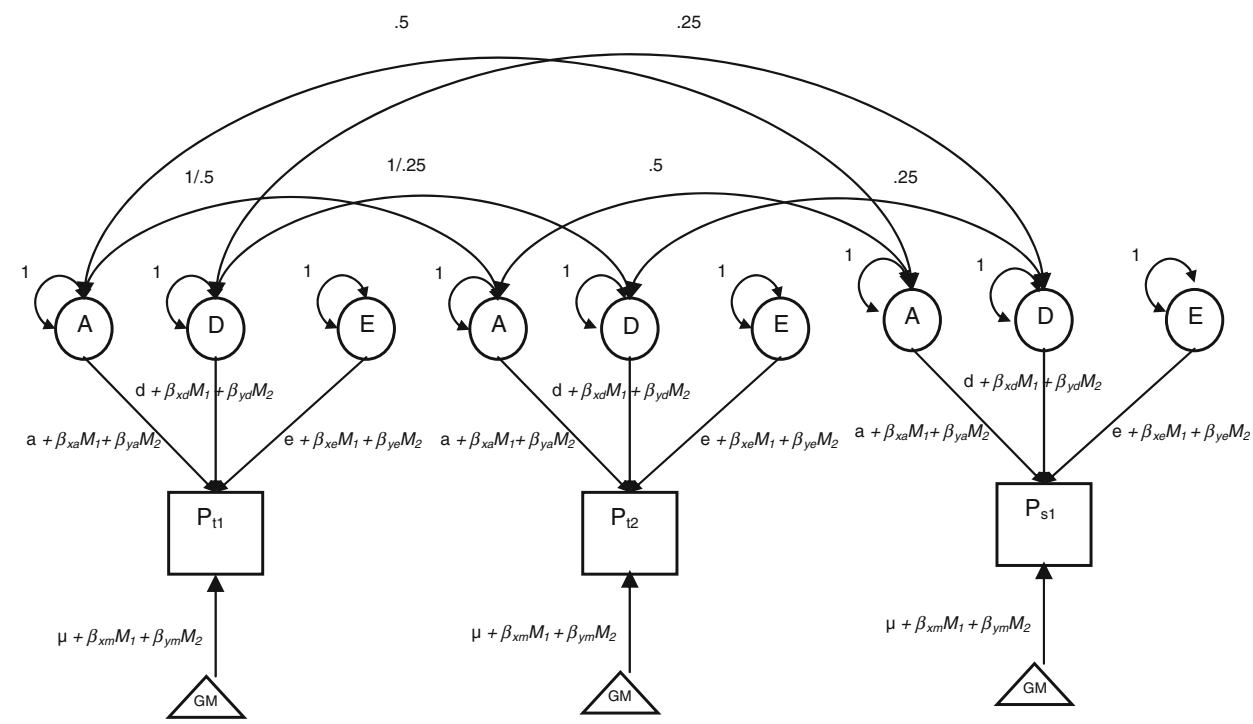




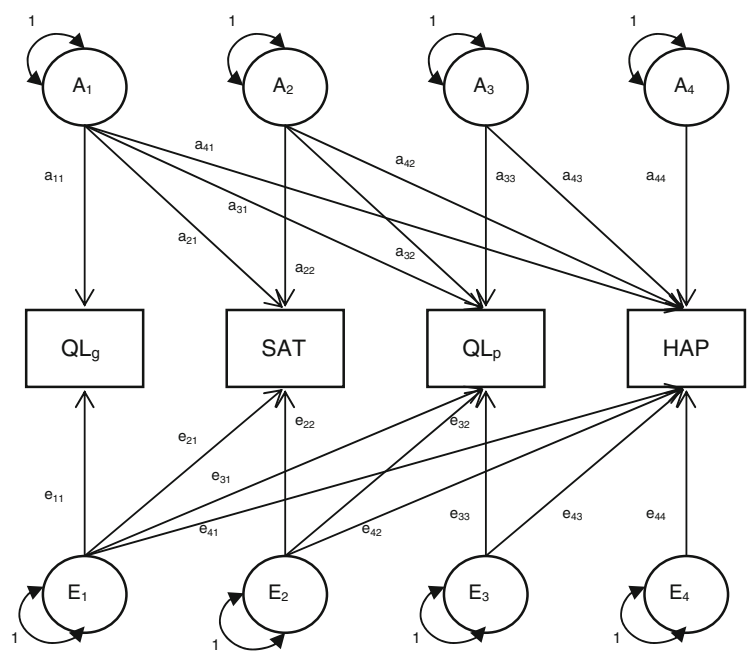

Fig. 2 Cholesky Decomposition for the four measures of SWB for a single person Squares represent measured variables, and circles represent latent, unobserved factors. A represents additive genetic effects, and $\mathrm{E}$ is unique environment. Their influence on the phenotype is given by path coefficients $a$ and $e$. For sake of clarity, the D component is left out of the picture. $\mathrm{QL}_{\mathrm{g}}=$ Quality of Life in General; SAT $=$ Satisfaction with life; $\mathrm{QL}_{\mathrm{p}}=$ Quality of life at present; HAP $=$ Subjective Happiness

cholesky decomposition was fit to the data first. This saturated model decomposes the phenotypic covariance matrix into additive genetic, non-additive genetic, and nonshared environmental matrices (see Fig. 2). Because the saturated model is fully parameterized, it yields the best possible fit to the data and can be used as a reference to evaluate the fits of more restricted, theoretically driven models. These included a correlated factor model, a common pathway model, and an independent pathway model.

To test for a possible distinction between a cognitive and affective component for SWB a correlated factor model, for the A, D, and E structure separately, was fitted to the data (see Fig. 3). In this model two latent factors were specified, one factor representing the cognitive component of SWB $\left(\mathrm{QL}_{\mathrm{g}}\right.$ and $\left.\mathrm{SAT}\right)$ and the other representing the emotional component $\left(\mathrm{QL}_{\mathrm{p}}\right.$ and HAP). Since dependence of these two latent factors is expected the factors were allowed to correlate $(r)$. Uncorrelated residual variance was captured in measure specific latent factors. For the identification of the two factor model, factor loadings for each factor were set equal $\left(a_{11}=a_{21}\right.$ and $a_{32}=a_{42}$ in Fig. 3).

Since the evidence for the existence of a clear distinction between a cognitive and affective component is scarce, the next model we fitted to the data was a common pathway model, which assumes that the phenotypic overlap between the four observed measures of SWB is determined by a single 'phenotypic' latent variable (SWB). The latent factor SWB is influenced by additive genetic, dominant

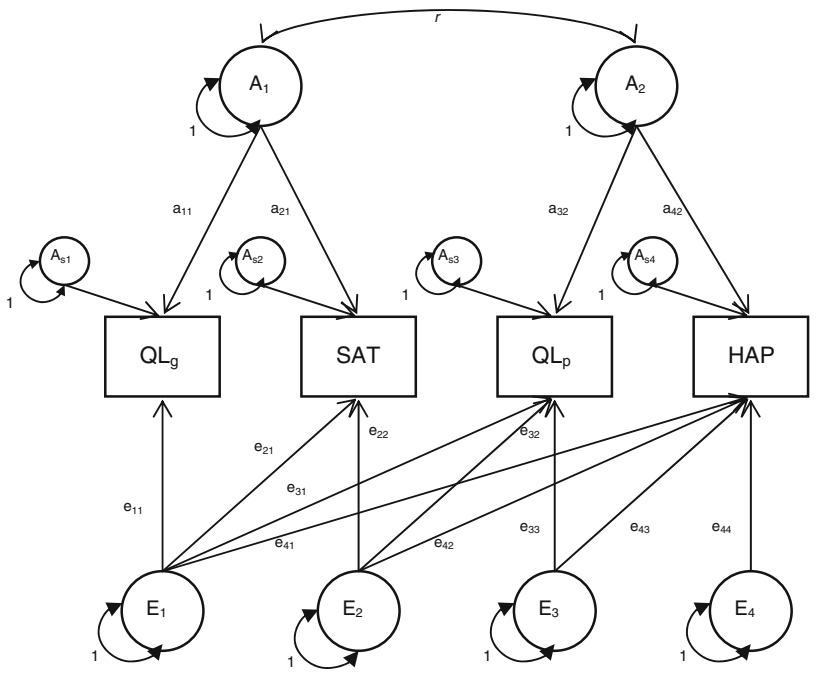

Fig. 3 The correlated two factor model for the four measures of SWB for a single person. Squares represent measured variables, and circles represent latent, unobserved factors. $A_{1}$ and $A_{2}$ represent the two underlying correlated latent factors. $A_{s 1}$ to $A_{s 4}$ represent measure specific additive genetic effects. $\mathrm{E}$ is unique environment. Their influence on the phenotype is given by path coefficients $a$ and $e$. For sake of clarity, the D component is left out of the picture, but could also be represented as a correlated factor model. $\mathrm{QL}_{\mathrm{g}}=$ Quality of Life in General; SAT $=$ Satisfaction with life; $\mathrm{QL}_{\mathrm{p}}=$ Quality of life at present; HAP $=$ Subjective Happiness

genetic and nonshared environmental factors. This model also includes measure specific factors (see Fig. 4). Significance of the measurement specific influences was tested by constraining them at zero. For model identification the variance of the latent SWB variable is constrained to be 1 . Finally, an independent pathway model is fitted to the data. In this model $\mathrm{A}, \mathrm{D}$, and $\mathrm{E}$ were specified to represent common factors underlying all four measures of SWB. Because each of the three common factors (A, D, and E) has its own path to each of the four variables, the model is called the independent pathway model. The model also includes measure specific factors (see Fig. 5). Significance of the measurement specific influences was tested by constraining them at zero.

\section{Results}

Descriptive statistics and correlations

No significant differences in means were found between males and females $\left(\chi_{4}^{2}=0, P=1.0\right)$. The small negative age effect on the means was significant $\left(\chi_{4}^{2}=40.45\right.$, $P=.00$ ), indicating that adolescents scored higher on subjective well-being than young adults $\left(\mathrm{QL}_{\mathrm{g}}:-.04 ; \mathrm{QL}_{\mathrm{p}}:-.06\right.$ SAT: -.11; HAP -.08). Grand means (uncorrected for age) 


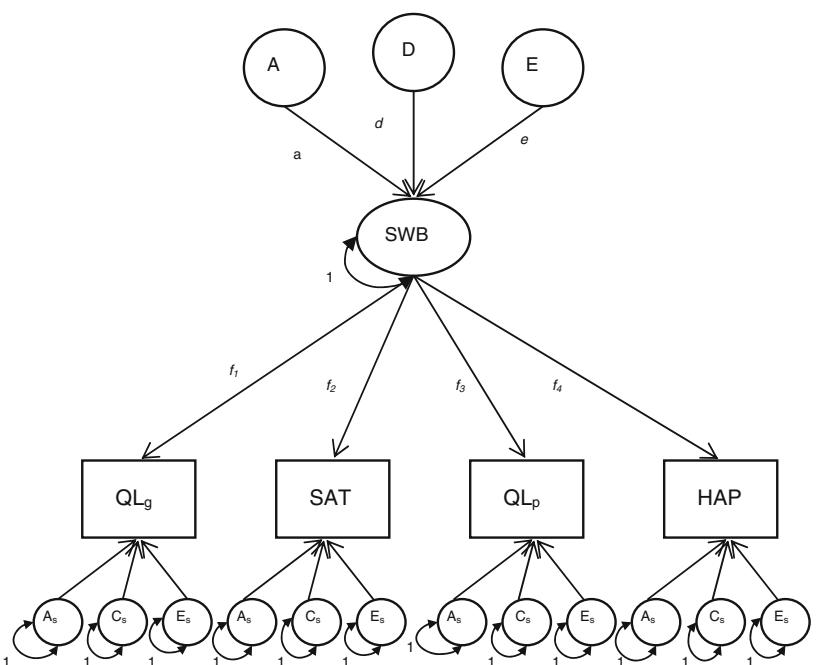

Fig. 4 The Common Pathway model for the four measures of SWB for a single person. Squares represent measured variables, and circles represent latent, unobserved factors. The bigger circle with 'SWB; in the middle represents the latent "phenotypic factor. A, D, and $\mathrm{E}$ represent the Additive genetic, dominant genetic, and nonshared environmental influences on this latent factors. Their influence on the phenotypic latent factor is given by path coefficients $a$, $d$, and $e$. Residual variance is depicted with the measurement specific latent factors $\left(\mathrm{A}_{\mathrm{s}}, \mathrm{D}_{\mathrm{s}}\right.$, and $\left.\mathrm{E}_{\mathrm{s}}\right) . \mathrm{QL}_{\mathrm{g}}=$ Quality of Life in General; $\mathrm{SAT}=$ Satisfaction with life; $\mathrm{QL}_{\mathrm{p}}=$ Quality of life at present; HAP $=$ Subjective Happiness

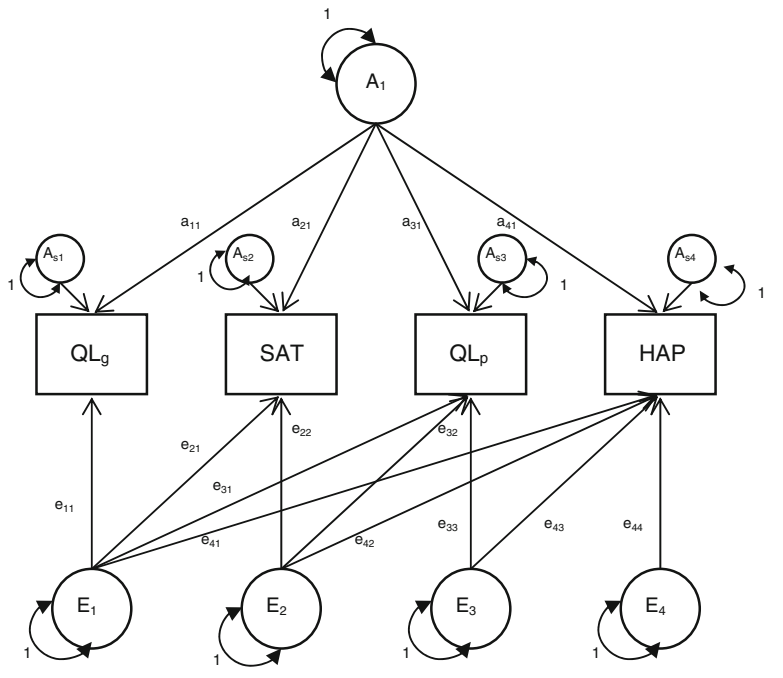

Fig. 5 The Independent Pathway model for the four measures of SWB for a single person. Squares represent measured variables, and circles represent latent, unobserved factors. $A_{1}$ represent the underlying latent additive genetic factors. $A_{\mathrm{s} 1}$ to $A_{s 4}$ represent measure specific additive genetic effects. $\mathrm{E}$ is unique environment. Their influence on the phenotype is given by path coefficients $a$ and $e$. For sake of clarity, the D component is left out of the picture, but could also be represented as an independent pathway model. $\mathrm{QL}_{\mathrm{g}}=$ Quality of Life in General; SAT $=$ Satisfaction with life; $\mathrm{QL}_{\mathrm{p}}=$ Quality of life at present; HAP $=$ Subjective Happiness
Table 1 Maximum likelihood estimates of phenotypic correlations among four measures of subjective well being (correlations in men above the diagonal and correlations in women below the diagonal)

\begin{tabular}{lcccc}
\hline & $\mathrm{QL}_{\mathrm{g}}$ & $\mathrm{SAT}$ & $\mathrm{QL}_{\mathrm{p}}$ & $\mathrm{HAP}$ \\
\hline $\mathrm{QL}_{\mathrm{g}}$ & & .52 & .50 & .47 \\
$\mathrm{SAT}$ & .62 & & .35 & .73 \\
$\mathrm{QL}_{\mathrm{p}}$ & .59 & .45 & & .37 \\
$\mathrm{HAP}$ & .59 & .77 & .48 &
\end{tabular}

$\mathrm{QL}_{\mathrm{g}}=$ Quality of Life in General; SAT = Satisfaction with life; $\mathrm{QL}_{\mathrm{p}}=$ Quality of life at present; HAP $=$ Subjective Happiness

for the four measures of SWB were estimated at 8.3 for $\mathrm{QL}_{\mathrm{g}}$, 28.3 for SAT, 8.9 for $\mathrm{QL}_{\mathrm{p}}$, and 23.1 for HAP. Sex differences in variance were found $\left(\chi_{50}^{2}=83.14, P=.002\right)$. However, no zygosity/sibling effect on variances was observed $\left(\chi_{60}^{2}=56.53, P=.6\right)$. For all 4 measures, covariances were equal for DZ twin and twin-sib pairs within sex $\left(\chi_{40}^{2}=47.96, P=.18\right)$.

Within person cross- trait correlations are presented in Table 1. These correlations were in the range of .35-.73 for males and .45-.77 for females, indicating a moderate to large overlap between the four measures of SWB.

Cross-person-cross trait correlations for the four SWB measures are presented in Table 2. Twin-sib correlations indicate genetic influences on all measures, since the MZ correlations are higher than the DZ and the twin-sib correlations. Effects of non-additive genetic factors are to be expected, since the DZ/sib correlations are much smaller

Table 2 Twin-sib correlations and cross-correlations. On the diagonal MZ/DZ-sib correlations are given, off-diagonal gives the MZ cross-correlations above and DZ-SIB cross-correlations below the diagonal

\begin{tabular}{cllll}
\hline & $\mathrm{QL}_{\mathrm{g}}$ & $\mathrm{SAT}$ & $\mathrm{QL}_{\mathrm{p}}$ & $\mathrm{HAP}$ \\
\hline Men & & & & \\
$\mathrm{QL}_{\mathrm{g}}$ & $.42 / .10$ & .30 & .26 & .28 \\
$\mathrm{SAT}$ & .07 & $.44 / .08$ & .20 & .40 \\
$\mathrm{QL}_{\mathrm{p}}$ & .06 & .06 & $.40 / .09$ & .21 \\
HAP & .09 & .09 & .08 & $.31 / .08$ \\
Women & & & & \\
QL & $.53 / .26$ & .40 & .38 & .36 \\
SAT & .23 & $.48 / .22$ & .28 & .40 \\
QL & .20 & .13 & $.32 / .15$ & .31 \\
HAP & .21 & .19 & .12 & $.46 / .17$
\end{tabular}

Opposite sex

$\mathrm{QL}_{\mathrm{g}} \quad .16$

SAT $\quad .12$

$\mathrm{QL}_{\mathrm{p}} \quad .13$

.17

HAP $\quad .12$

.09

.21

$.14 \quad .12$

.15

$\mathrm{QL}_{\mathrm{g}}=$ Quality of Life in General; SAT = Satisfaction with life; $\mathrm{QL}_{\mathrm{p}}=$ Quality of life at present; HAP $=$ Subjective Happiness 
than the MZ correlations. Male-female correlations do not suggest the expression of different genes in men and women. The MZ-DZ/sib differences in the cross-trait correlations, represented in Table 2 by the off-diagonal elements, indicate that the phenotypic correlations between the four measures of SWB are at least partly accounted for by genetic influences.

Age and sex effects- the moderator model

Model fitting started with an ADE model for all four measures of SWB. Age moderation was not significant for additive genetic, non-additive genetic and nonshared environmental effect for any of the SWB measures (all p-values $>.05)$. Sex moderation was only significant for additive genetic influences on $\mathrm{QLg}(P=.011)$ and nonshared environmental influences on HAP $(P=.023)$.

Correlated factor, common pathway, and independent pathway models

Table 3 presents the multivariate model fitting results. A correlated two factor model did in general not describe the data well. The common pathway model, with a phenotypic latent factor for SWB provided a bad fit. An independent pathway model for both $\mathrm{A}$ and $\mathrm{D}$, however, fitted the data well. Measurement specific genetic influences, were only present for non-additive genetic influences on QLg and HAP, but not for SAT and QLp. Nonshared environmental influences were best captured by a cholesky decomposition. The best fitting model (AIC $=-14.13$; see Fig. 6) is a model with an independent pathway specification for $\mathrm{A}$ and D, and a cholesky decomposition for E. The only significant residual variance was the small influence of $\mathrm{D}$ on $\mathrm{QL}_{\mathrm{g}}$ and HAP.

Table 4 provides standardized estimates of additive genetic, non-additive genetic, and nonshared environmental influence on variances and covariance based on the best fitting model. Thirty-six to $50 \%$ of the individual differences in SWB are accounted for by genetic factors, while the remaining variance is accounted for by nonshared environmental factors. Significant non-additive genetic effects are found, with a low estimate for Quality of life at present, but moderate estimates for the remaining three measures $(.25, .38, .26$ for QLg, SAT, and HAP, respectively). Over $50 \%$ of the overlap between the four measures was accounted for by genetic effects (see Table 4).

\section{Discussion}

There are several constructs reflecting subjective wellbeing. One way to distinguish the different constructs is along the lines of cognitive versus emotionally driven subjective well-being. Another way to distinguish them is along a time line in which ad hoc feelings of well-being are distinguished from feeling well in general or over a longer time frame. Although discriminate validity between the cognitive component and the emotional component has been established (Lucas et al. 1996) and a time-sequential framework has been suggested (Kim-Prieto et al. 2005), no study focused on the underlying source of covariance of often used measures of well-being.

In the current study causes of individual differences of four measures of SWB and the underlying sources of overlap were investigated. We tested distinct multivariate

Table 3 Multivariate genetic model fitting: fit statistics

\begin{tabular}{|c|c|c|c|c|c|c|c|}
\hline Model & $-2 \mathrm{LL}$ & df & Compared to & $\chi^{2}$ & df & $P$ & AIC \\
\hline 1. Cholesky & $78,478.613$ & 18,654 & & & & & \\
\hline 2. A correlated factors & $78,486.713$ & 18,657 & 1 & 8.1 & 3 & .04 & 2.1 \\
\hline 3. D correlated factors & $78,484.431$ & 18,657 & 1 & 5.82 & 3 & .12 & -.18 \\
\hline 4. A \& D correlated factors & $78,712.089$ & 18,660 & 1 & 233.48 & 6 & .00 & 227.48 \\
\hline 5. Common pathway model + specifics & $78,999.185$ & 18,666 & 1 & 520.57 & 12 & .00 & 496.57 \\
\hline 6. A independent pathway + specific & $78,418.643$ & 18,656 & 1 & 3.03 & 2 & .21 & -.97 \\
\hline 7. D independent pathway + specific & $78,479.592$ & 18,656 & 1 & .98 & 2 & .61 & -.302 \\
\hline 8. A \& D independent pathway + specific & $78,484.418$ & 18,658 & 1 & 5.8 & 4 & .21 & -2.2 \\
\hline 9. No A specifics & $78,484.486$ & 18,662 & 7 & .07 & 4 & .99 & -7.93 \\
\hline 10. No D specifics & $78,497.516$ & 18,662 & 7 & 13.10 & 4 & .01 & 5.1 \\
\hline 11. No D specifics for SAT and QLp & $78,484.418$ & 18,660 & 7 & 0 & 2 & 1.0 & -4 \\
\hline 12. E independent pathway + specific & $78,540.053$ & 18,656 & 1 & 61.44 & 2 & .00 & 57.44 \\
\hline 13. E correlated factors & $79,457.058$ & 18,657 & 1 & 978.44 & 3 & .00 & 972.44 \\
\hline $\begin{array}{l}\text { 14. A \& D independent pathway; no A specific } \\
\text { D specifics for } \mathrm{Ql}_{\mathrm{g}} \& \text { HAP; E Cholesky }\end{array}$ & $78,484.486$ & 18,664 & 1 & 5.87 & 10 & .83 & -14.13 \\
\hline
\end{tabular}


Fig. 6 The best fitting model, with an independent pathway specification for both $\mathrm{A}$ and $\mathrm{D}$, and a cholesky decomposition for E. The only significant residual variance is found for dominant genetic influences on $\mathrm{QL}_{\mathrm{g}}$, and HAP. Unstandardized path coefficients are depicted in the figure

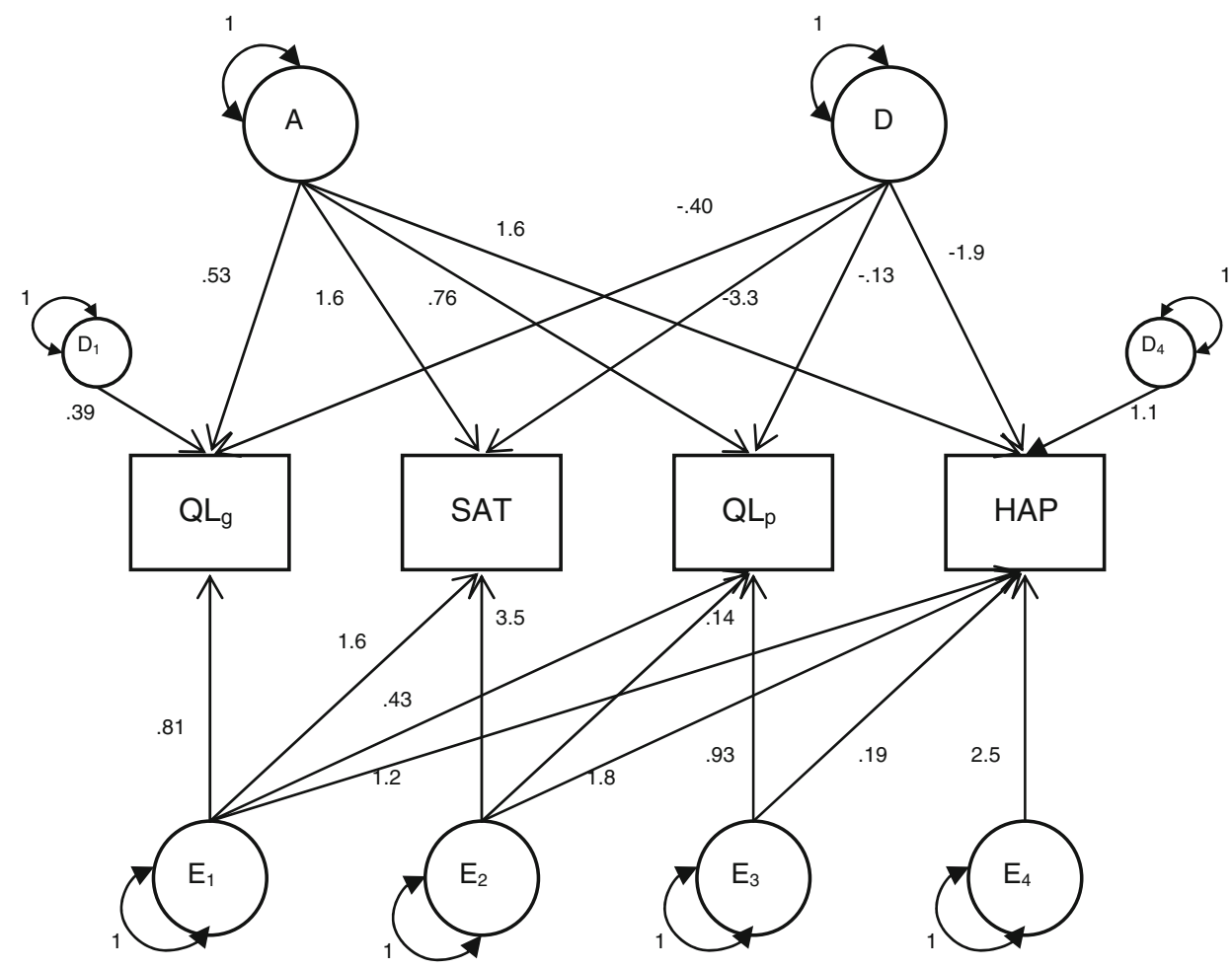

models to gain optimal insight into the causes of phenotypic clustering.

The best fitting model included an independent pathway specification for $\mathrm{A}$ and $\mathrm{D}$, and a cholesky decomposition for E. This finding in combination with the absence of measurement specific influences of additive genetic effects and only significant measurement specific non-additive genetic effects for Quality of life in general and Happiness, indicates that underlying sets of genes are responsible for the moderate to high phenotypic correlations. The implication of this finding is that distinct measures of SWB are not distinct at the genetic level. All four measures, used in this study, load on similar sets of genes. This makes comparison of different studies and collaboration by combining distinct datasets feasible.

We found that genetic and nonshared environmental influences explain individual differences in $\mathrm{QL}_{\mathrm{g}}, \mathrm{QL}_{\mathrm{p}}, \mathrm{SAT}$, and HAP. Broad heritabilities $(\mathrm{A}+\mathrm{D})$ are in the range of 36-50\%. Significant non-additive genetic influences are found for all four measures, accounting for up most $38 \%$ of the variance. Heritability estimates are in line with the findings of previous studies (Tellegen et al. 1988; Lykken and Tellegen 1996; Røysamb et al. 2002, 2003; Stubbe et al. 2005; Nes et al. 2006). Covariance between the four measures is mainly accounted for by additive and non-additive effects. Recently, doubts have been raised concerning the power to detect non-additive genetic effects and the possibility to distinguish these from sibling interaction/contrast effects in previous studies on SWB (Weiss et al. 2008). The current multivariate study, with a twin-sibling design, a sample size of over 5,000 individuals, and no evidence for variance differences between $\mathrm{MZ}$ and $\mathrm{DZ}$ twins, provides convincing evidence for the importance of non-additive genetic effects in explaining individual differences in SWB (Posthuma and Boomsma 2000; Rietveld et al. 2003). Sexdifferences are not of importance for either mean levels of SWB or for the genetic architecture. The absence of sexspecific genetic influences and the absence of age effects on the genetic architecture imply that for purposes of identifying and quantifying genetic and environmental influences on SWB sex and age are no matter of concern in adolescents and young adults. An effect of age on mean levels of SWB is found in our data spanning the age range from 12 to 23 . We find the expected small but significant negative effect of age on mean levels of SWB.

Our results may be of importance to psychology and psychiatry. The finding of the genetic overlap between the different measures of wellbeing fosters the field of positive psychology and its research. One of the growing topics within this field is the cross-cultural comparison of wellbeing (Diener et al. 2003). Our finding that a relative culture free measure, such as the Cantril ladder, shows complete genetic overlap with more culturally sensitive measures of life satisfaction, indicates that for international comparison simple measures could be used. Furthermore, studies that so far collected distinct measures of SWB can still be compared, 
based on the fact the distinct measures all load on a similar genetic factor, and thus represent biological overlapping constructs. Finally, our findings indicate that over half of the variance in SWB is accounted for by nonshared environmental influences. So, although it can be assumed that each individual has its, probably genetically determined, setpoint of SWB (Lykken 1999), influences of environmental factors unique to each individual are important. If we are able not only to quantify but also indentify these effects, we will learn what environmental factors make some people happier than others. A next step will be to use this information in the development of happiness intervention programs or psychopathology prevention programs. Obvious factors of importance are income (Clark et al. 2008; Stutzer 2004), education (Blanchflower and Oswald 2004; Bukenya et al. 2003), unemployment (Clark and Oswald 1994; Lucas et al. 2004), religion (Ciarrochi and Deneke 2005; Francis and Kaldor 2002), exercise (Stubbe et al. 2007; Biddle and Ekkekakis 2005), marriage (Brown 2000), friendship (Lelkes 2006; Pichler 2006), and economic/political environment (Kahneman et al. 2004; Di Tella et al. 2003), but overall effect sizes are found to be small, explaining 16-30\% of the variance in SWB, leaving the largest part of environmental variance in SWB unexplained. While some of the examples do not fit the age group studied in the current manuscript an overall explanation for the small effects on the variance, could be the fact that no study to date has allowed for gene-environment interplay when studying SWB, with the possibility that part of the environment will actually turn out to represent geneenvironment interaction. For example it has been found that religious people report greater happiness than their irreligious counterparts (e.g. Ciarrochi and Deneke 2005). Religion has also been studied in the context of geneenvironment interaction. Boomsma et al. (1999) found that religious upbringing significantly moderated the magnitude of genetic influences on the personality trait of behavioral disinhibition, with a smaller estimate of the importance of genetic influences for those who were raised religiously than those who were not raised religiously. Furthermore, higher heritabilities for the risk of alcohol use initiation in females without a religious upbringing compared to females with a religious upbringing have been reported (Koopmans et al. 1999). In this context, the question rises if religious upbringing modifies the genetic architecture of SWB. So, future research should focus on the complex interplay between genes and environment, without being concerned about which measure of SWB should be used.

Open Access This article is distributed under the terms of the Creative Commons Attribution Noncommercial License which permits any noncommercial use, distribution, and reproduction in any medium, provided the original author(s) and source are credited. 


\section{References}

Andrews FM, Withey SB (1976) Social indicators of well-being. Plenum Press, New York

Bartels M, Van Beijsterveldt CEM, Derks EM, Stroet TM, Polderman JC, Hudziak JJ et al (2007) Young netherlands twin register (YNTR): a longitudinal multiple informant study of problem behavior. Twin Res Hum Genet 10:3-11

Biddle SJH, Ekkekakis P (2005) Physical active lifestyles and wellbeing. In: Huppert FA, Baylis N, Keverne B (eds) The science of well-being. Oxford University Press, Oxford, pp 141-168

Blanchflower DG, Oswald AJ (2004) Well-being over time in Britain and the USA. J Public Econ 88:1359-1386

Boomsma DI, de Geus EJC, van Baal GCM, Koopmans JR (1999) A religious upbringing reduces the influence of genetic factors on disinhibition: Evidence for interaction between genotype and environment on personality. Twin Res 2:115-125

Boomsma DI, de Geus EJC, Vink JM, Stubbe JH, Distel MA, Hottenga JJ et al (2006) Netherlands twin register: from twins to twin families. Twin Res Hum Genet 9:849-857

Brown SL (2000) The effect of union type on psychological wellbeing: depression among cohabitors versus marrieds. J Health Soc Behav 41:241-255

Bukenya JO, Gebremedhin TG, Schaeffer PV (2003) Analysis of rural quality of life and health: a spatial approach. Econ Dev Q 17(3):280-293

Calman KC (1984) Quality of life in cancer patients-an hypothesis. J Med Ethics 10(3):124-127

Cantril H (1965) The pattern of human concerns. Rutgers University Press, New Brunswick, NJ

Ciarrochi JW, Deneke E (2005) Happiness and the varieties of religious experience: religious support, practices, and spirituality as predictors of well-being. Res Soc Sci Study Relig 15:209-223

Clark A, Oswald A (1994) Unhappiness and unemployment. Econ J 104(424):648-659

Clark A, Frijters P, Shields MA (2008) A survey of the income happiness gradient. J Econ Lit 46(1):95-144

Cohn MA, Fredrickson BL, Brown SL, Mikels JA, Conway AM (2009) Happiness unpacked: positive emotions increase life satisfaction by building resilience. Emotion 9(3):361-368

Currie C et al (eds) (2008) Inequalities in young people's health: HBSC international report from the 2005/2006 Survey. WHO Regional Office for Europe, Copenhagen (Health Policy for Children and Adolescents, No. 5)

Di Tella R, MacCulloch R, Oswald A (2003) The macroeconomics of happiness. Rev Econ Stat 85(4):809-827

Diener E (2005) Satisfaction with life scale. http://www.psych.uiuc. edu/yediener/hottopic/hottopic.html). Accessed 6 April 2005

Diener E, Emmons RA (1984) The independence of postive and negative affect. J Pers Soc Psychol 47:1105-1117

Diener E, Emmons RA, Larsen RJ, Griffin S (1985) The satisfaction with life scale. J Pers Assess 49:71-75

Diener E, Suh E, Oishi S (1997) Recent findings on subjective wellbeing. Indian J Clin Psychol 24(1):25-41

Diener E, Suh EM, Lucas RE, Smith HE (1999) Subjective wellbeing: three decades of progress. Psychol Bull 125:276-302

Diener E, Oishi S, Lucas RE (2003) Personality, culture, and subjective well-being: emotional and cognitive evaluations of life. Annu Rev Psychol 54:403-425

Dijkers MP (2005) Quality of life of individuals with spinal cord injury: a review of conceptualization, measurement, and research findings. J Rehabil Res Dev 42(3 Suppl 1):87-110

Dijkers MP (2007) "What's in a name?" The discriminating use of the "Quality of life" label, and the need to bring about clarity in conceptualizations. Int J Nurs Stud 44:153-155
Eaves LJ, Heath AC, Martin NG, Neale MC, Meyer JM, Silberg JL, Corey LA, Truett K, Walters E (1999) Biological and cultural inheritance of stature and attitudes. In: Cloninger CR (ed) Personality and psychopathology. American Psychopathological Association, Washington

Ferrans CE (1996) Development of a conceptual model of quality of life. Sch Inq Nurs Pract 10(3):293-304

Francis LJ, Kaldor P (2002) The relationship between psychological well-being and Christian faith and practice in an Australian population sample. J Sci Study Relig 49:179-184

Kahneman D, Krueger AB, Schkade DA, Schwarz N, Stone AA (2004) Toward national well-being accounts. Am Econ Rev 94(2):429-434

Kim-Prieto C, Diener E, Tamir M, Scollon CN, Diener M (2005) Integrating the diverse definitions of happiness: a time-sequential framework of subjective well-being. J Happiness Stud 6:261-300

Koopmans JR, Slutske WS, van Baal GCM, Boomsma DI (1999) The influence of religion on alcohol use initiation: evidence for genotype X environment interaction. Behav Genet 29:445-453

Larsen RJ, Ketelaar T (1991) Personality and susceptibility to positive and negative emotional states. J Pers Soc Psychol 61(1):132-140

Lelkes O (2006) Knowing what is good for you. Empirical analysis of personal preferences and the "objective good". J Socio Econ 35(28):5-307

Lucas RE, Diener E, Suh E (1996) Discriminant validity of wellbeing measures. J Pers Soc Psychol 71(3):616-628

Lucas RE, Clark AE, Georgellis Y, Diener E (2004) Unemployment alters the set point for life satisfaction. Psychol Sci 15(1):8-13

Lykken D (1999) Happiness: What studies of twins show us about nature, nurture, and the happiness set-point. Golden Books, New York

Lykken D, Tellegen A (1996) Happiness is a stochastic phenomenon. Psychol Sci 7:186-189

Lyubomirsky S, Lepper HS (1999) A measure of subjective happiness: preliminary reliability and construct validation. Soc Indic Res 46:137-155

Meeberg GA (1993) Quality of life: a concept analysis. J Adv Nurs 18(1):32-38

Moons P, Budts W, De Geest S (2006) Critique on the conceptualisation of quality of life: a review and evaluation of different conceptual approaches. Int J Nurs Stud 43(7):891-901

Moum T, Ness S, Sorensen T, Tambs K, Holmen T (1990) Hypertension labeling, life events, and psychological well-being. Psychol Med 20:635-646

Neale MC, Boker SM, Xie G, Maes HH (2006) Mx: statistical modeling, 7th edn. VCU Department of Psychiatry, Richmond

Nes RB, Røysamb E, Tambs K, Harris JR, Reichborn-Kjennerud T (2006) Subjective well-being: genetic and environmental contributions to stability and change. Psychol Med 6(7):1033-1042

Pichler F (2006) Subjective quality of life of young Europeans. Feeling happy but who knows why? Soc Indic Res 75(41):9-444

Posthuma D, Boomsma DI (2000) A note on the statistical power in extended twin designs. Behav Genet 30:147-158

Purcell S (2002) Variance components models for gene-environment interaction in twin analysis. Twin Res 5(6):554-571

Rietveld MJ, van Der Valk JC, Bongers IL, Stroet TM, Slagboom PE, Boomsma DI (2000) Zygosity diagnosis in young twins by parental report. Twin Res 3(3):134-141

Rietveld MJH, Posthuma D, Dolan CV, Boomsma DI (2003) ADHD: sibling interaction or dominance: an evaluation of statistical power. Behav Genet 33:247-255

Røysamb E, Harris JR, Magnus P, Vitterso J, Tambs K (2002) Subjective well-being. Sex-specific effects of genetic and environmental factors. Pers Individ Dif 32:211-223

Røysamb E, Tambs K, Reichborn-Kjennerud T, Neale MC, Harris JR (2003) Happiness and health: environmental and genetic contri- 
butions to the relationship between subjective well-being, perceived health, and somatic illness. J Pers Soc Psychol 85:1136-1146

Stubbe JH, Posthuma D, Boomsma DI, de Geus EJC (2005) Heritability of life satisfaction in adults: a twin-family study. Psychol Med 35:1581-1588

Stubbe JH, de Moor MHM, Boomsma DI, de Geus EJC (2007) The association between exercise participation and well-being: a cotwin study. Prev Med 44:148-152

Stutzer A (2004) The role of income aspirations in individual happiness. J Econ Behav Organ 54:89-109

Tellegen A, Lykken DT, Bouchard TJ, Wilcox KJ, Rich S, Segal NL (1988) Personality similarity in twins reared apart and together. J Pers Soc Psychol 54:1031-1039
Tugade MM, Fredrickson BL (2004) Resilient individuals use positive emotions to bounce back from negative emotional experiences. J Pers Soc Psychol 86:320-333

UNICEF (2007) Child poverty in perspective: an overview of child well-being in rich countries, Innocenti report card 7. UNICEF Innocenti Research Centre, Florence

Weiss A, Bates TC, Luciano M (2008) Happiness is a personal(ity) thing: the genetics of personality and well-being in a representative sample. Psychol Sci 19(3):205-210

Zhan L (1992) Quality of life: conceptual and measurement issues. J Adv Nurs 17(7):795-800 